Academic Platform Journal of Engineering and Science

journal homepage: http://apjes.com/

\title{
Çok Kriterli Karar Verme Yöntemleriyle Taşeron Firma Seçimi: Kırıkkale İlinde Bir Uygulama
}

\author{
${ }^{1}$ Neşet Bedir(0000-0002-8906-9194), ${ }^{2}$ Hamza Yalçın(0000-0002-8084-5606), ${ }^{3}$ Emir Hüseyin Özder(0000-0002-1895-8060), \\ 4*Tamer Eren(0000-0001-5282-3138) \\ ${ }^{1}$ Kırıkkale Üniversitesi, Mühendislik Fakültesi, Endüstri Mühendisliği Bölümü, nstbdr@gmail.com \\ ${ }^{2}$ Kırıkkale Üniversitesi, Mühendislik Fakültesi, İnşaat Mühendisliği Bölümü, hamzayalcin06@ hotmail.com \\ ${ }^{3}$ Başkent Üniversitesi, Ticari Bilimler Fakültesi, Yönetim Bilişim Sistemleri Bölümü, ehozder@baskent.edu.tr \\ ${ }^{4}$ Kırıkkale Üniversitesi, Mühendislik Fakültesi, Endüstri Mühendisliği Bölümü, teren@kku.edu.tr
}

Geliş Tarihi: 13.07.2017 Kabul Tarihi: 31.05.2018

Öz

Günümüz piyasalarında firmaların hayatta kalabilmeleri için rekabet etmeleri gerekmektedir. Arz talep dengesinin yön değiştirdiği günümüzde, firmalar, asıl işlerini kendileri yapıp diğer işlerini o alanda çalışan yetkin firmalara bırakmaktadırlar. Bu sayede iş gücü ve malzeme envanterlerini minimum seviyede tutarak fazla işgücü ve stok maliyetlerinden kurtulmaktadırlar. Taşeron işçiler günümüzde birçok şirket tarafından yardımcı işlerde kullanılmaktadır. Bunun başlıca sebebi büyük işletmeler için dış kaynak kullanımı yoluyla esas yaptıkları üretime odaklanmak iken küçük işletmeler için kendi bünyesinde çalıştırdıkları işçilerin sigorta, sosyal imkân, vb. masraflarından kurtularak üzerlerindeki bu yükü atarak daha fazla kâr etmektir. Gayrimenkul ve proje şirketleri de ev satmanın yanında tadilat işleri de yapmaktadır. Bunun için taşeron firma kullanmaktadırlar. Taşeron firma kullanımına en fazla ihtiyaç duyulan sektörlerden birisi de inşaat sektörüdür. Bu amaçla Kırıkkale ilinde faaliyet gösteren bir gayrimenkul ve proje şirketinin anahtar teslim tadilat işi için taşeron firma seçimi problemi ele alınmıştır. Problemin çözümünde çok kriterli karar verme (ÇKKV) yöntemlerinden Analitik Ăg Süreci ve PROMETHEE yöntemlerinden yararlanılmıştır. Taşeron firma seçimine etkiyen kriterlerin ağırlıklarının belirlenmesinde Analitik A $\breve{g}$ Süreci yöntemi kullanılmıştır. Analitik A ̆g Süreci yöntemi ile bulunan kriter ağırlıkları kullanılarak PROMETHEE yöntemi ile alternatif firmaların sıralaması yapılmıştır. PROMETHEE I kısmi sıralama sonucuna göre MAK firması diğer alternatiflere tam üstünlük sağlarken, diğer alternatiflerin net sıralaması çıkarılamamaktadır. Bu sebeple PROMETHEE II ile net üstünlükler sıralandığında yine MAK şirketi net üstünlük sağlayarak yapılacak işi almıştır.

Anahtar kelimeler: Dış kaynak kullanımı, Analitik Ă̆ Süreci, PROMETHEE, Çok Kriterli Karar Verme

\section{Subcontractor Company Selection with Multiple Criteria Decision Making: An application in Kurıkkale}

\author{
${ }^{1}$ Neşet Bedir, ${ }^{2}$ Hamza Yalçın, ${ }^{3}$ Emir Hüseyin Özder, ${ }^{4 *}$ Tamer Eren \\ ${ }^{1}$ Kirıkkale University, Faculty of Engineering, Department of Industrial Engineering, nstbdr@gmail.com \\ ${ }^{2}$ Kırıkkale University, Faculty of Engineering, Department of Civil Engineering,, hamzayalcin06@ hotmail.com \\ ${ }^{3}$ Başkent University, Faculty of Commercial Science, Department of Management Information Systems, \\ ehozder@baskent.edu.tr \\ ${ }^{4}$ Kırikkale University, Faculty of Engineering, Department of Industrial Engineering, teren@kku.edu.tr
}

\begin{abstract}
Competition is necessary for companies to survive in today's markets. To change the direction of supply demand equilibrium nowadays, the firm is authorized to make according to others and to act according to others. On this basis, they keep their labor and material inventories at a minimum level to get rid of labor and inventory costs. Subcontractor workers are now used in many aids for many companies. The main reason for this is the outsourcing principles for large enterprises, the focus is on production, while for small businesses workers themselves employ insurance, social facilities, and so on. to make more profit by getting rid of the costs and throwing this burden on them. Real estate and project companies also do renovation works. It uses a subcontractor
\end{abstract}


for this. One of the most needed sectors for subcontractor use is the construction sector. For this purpose, the problem of subcontractor selection for a turnkey renovation work of a real estate and project company operating in the province of Kirikkale has been discussed. It is based on the method of multi-criteria decision making (MCDM) methods and it is benefited from Ağrı Süreci and PROMETHEE methods. The Method of Aperture Process is used. PROMETHEE method was used to rank the companies selected. PROMETHEE According to the result of the partial selection, the MAK firm provides a superiority to the other alternatives, but the net order of the other alternatives can not be obtained. For this reason, when PROMETHEE II is listed as a net superiority, again MAK company has got a net profit and got the job to be done first.

Keywords: Outsourcing, ANP, PROMETHEE, Multi-criteria Decision Making

\section{GİRIS}

Teknolojik gelişmelerle beraber değișen ekonomi dünyasında işletmeler birbirleriyle sürekli iletişim halindedirler. İşletmeler önceleri yalnızca hammadde, ara ürün, yarı mamul, yedek parça ve sarf malzemeler için dış kaynak kullanırken, günümüzde ürünü direk olarak başka işletmelerden alabilmekte hatta işin tamamı için diş kaynak kullanımı yoluna gidebilmektedirler.

Dış kaynak kullanımında işletmeler yapılacak olan işleri uygun taşeron firma aracılıyla yaptıkları takdirde hem zamandan, hem mekândan hem de paradan tasarruf ederler. Özellikle inşaat sektöründe taşeron kullanımı büyük önem teşkil etmektedir. İnşaatın hemen hemen bütün aşamaları taşeron firmalar aracılığıyla taşeron işçiler tarafından yapılmaktadır. Taşeron firma seçimi bu noktada çok kriterli bir problem haline dönüşür. Birden çok kriterin bir arada değerlendirilmesi gereken problemlerin çözümünde çok kriterli karar verme yöntemi kullanılır.

Karar verme, karşılaşılan bir sorun karşısında beklentileri en iyi şekilde karşılayacak alternatifi seçme eylemidir. Literatürde en sık rastlanan çok kriterli karar verme problemleri AHP, ANP (Analitik Ă̆ süreci), TOPSIS, ELECTRE, PROMETHEE (Preference Ranking Organization Method of Enrichment evaluation) ve VIKOR'dur.

Bu çalışmada Kırıkkale de faaliyet gösteren bir müteahhit firmasının anahtar teslim tadilat işlerini yaptırmak için sektördeki taşeron firmalardan

hangisi ile çalışacağ 1 belirlenmiştir. Problemin çözümü için çok kriterli karar verme yöntemlerinden ANP, ve PROMETHEE yöntemleri birlikte kullanılmıştır. Öncelikle ANP yöntemi ile seçilecek olan firmaların değerlendirme kriterlerinin ağırlıkları belirlenmiştir. Elde edilen kriter ağırlıkları kullanılarak aday firmaların sıralanması için PROMETHEE yöntemi kullanılmıştır.

Çalışmanın planı şu şekildedir. İkinci bölümde taşeron firma seçim problemi tanımlanmıştır. Üçüncü bölümde taşeron firma seçimi ile ilgili literatürde yapılan çalışmalar incelenmiştir. Dördüncü bölümde çok kriterli karar verme yöntemleri anlatılmıştır. Beşinci bölümde taşeron firma seçimi probleminin uygulaması anlatılmıştır. Son bölümde sonuçlar değerlendirilmiştir.

\section{TAŞERON FIRMA SEÇİMI}

Müteahhitler almış oldukları projeleri yetiştirebilmek için projenin tamamını ya da bir kısmını taşeron firma eliyle yaptırmaktadır. Bu durumda iş yaptırılacak olan firmalar işin gerekliliklerine uygun olarak seçilmelidir. Firmaların seçilmesini etkiyen özellikler doğru belirlenirse yapılan iş istenilen kalitede olur. Bir işin bir bölümünü, esas işi yapan kurum ya da kişiden alarak, o işi yapmaya başlayan kişi, kurum ya da firmaya taşeron adı verilir. Taşeron kavramı yasalarda "alt işveren" olarak geçmektedir. Taşeron iş yapan firmalarda çalışan işçilere taşeron işçi denir.

Taşeron işçiler bir işin esas bölümünde değil de işin asıl yürümesine yardımcı olan yan kollarda görevlendirilebilir.

\section{LITERATÜRDE YER ALAN ÇALIŞMALAR}

$\mathrm{Bu}$ bölümde literatürde taşeron firma seçimi ile ilgili yapılan çalışmalara yer verilmiştir.

Hatush ve Skitmore [1] çok katlı bir bina projesisin yapılması için 5 alternatif firmadan hangisinin seçileceğini çok kriterli fayda teorisi kullanarak belirlemişlerdir. Topçu [2] çalışmasında Türk kamu sektöründe müteahhit seçimi için çok amaçlı karar verme modeli önermişlerdir. Önerdikleri modelin uygun yüklenici seçiminde proje sahipleri tarafından karar destek sistemi olarak kullanılmasını amaçlamışlardır. Mulavdic [3], sürdürülebilir gelişim çerçevesinde, konut tipi seçimine ilişkin çalışmasında VIKOR yöntemini uygulamışlardır. Gül [4] çalışmasında dış kaynak kullanımın taşıdığı riskleri imalat sektöründe bir uygulamayla anlatmıştır. Singh ve Tiong [5] yüklenici firma seçimi için bulanık mantıktan faydalanmışlardır. Maliyet, zaman, kalite ve işgücü kriterlerine göre alternatifleri değerlendirerek en uygun yükleniciyi seçmişlerdir. Tzeng vd. [6], yapmış oldukları çalışmada toplu taşımada kullanılacak alternatif yakıtların değerlendirmesinde VIKOR ve TOPSIS yöntemlerini kullanmışlardır. Soner ve Önüt [7] çalışmalarında tedarikçi seçimi için AHP ve ELECTRE yöntemlerini kullanmışlardır. Opricovic [8] su kaynakları planlamasında VIKOR yöntemini kullanmıştır. Chu vd. [9] çalışmalarında bilgi yönetim alanında ortaya çıkan çok kriterli karar verme yöntemlerini değerlendirmişlerdir ve TOPSIS ve VİKOR yönteminin gerçeğe daha yakın sonuçlar verdiğini saptamışlardır. Lixin vd. [10] çalışmalarında 4 farklı alternatif içerisinden iyi lojistik servis sağlayıcının seçimini ANP ve VIKOR yöntemini kullanarak yapmışlardır. 
VİKOR yönteminin uygulamada daha kolay olduğunu saptamışlardır. Wua vd. [11] çalışmalarında performans ölçümü amacıyla AHP ve VİKOR yöntemini kullanarak üç bankayı yirmi üç kriter kapsamında bulanık ortamda analiz etmişlerdir. Ertuğrul ve Karakaşoğlu [12] çalışmalarında Ege bölgesindeki banka şubelerinin performansını ölçmek amacıyla VIKOR yöntemini kullanmışlardır. Sanayei vd. [13] çalışmalarında bulanık ortamdaki tedarikçi seçim problemi için VIKOR yöntemini kullanmışlardır. Kaya ve Kahraman [14] yenilenebilir enerji alternatiflerinin seçimi problem için, AHP ve VIKOR yöntemlerini kullanarak bulanık ortamda bir analiz gerçekleştirmişlerdir. Akyüz [15] çalışmasında mobilya parçaları üreten bir firmanın ambalaj tedarikçisi seçim probleminde ÇKKV yöntemlerinden Bulanık VIKOR'u kullanmışlardır. Ravi [16] çalışmasında üçüncü parti lojistik firma seçimi için AHP ve TOPSIS yöntemlerini kullanımıştır. Abbasianjahromi vd. [17] çalışmalarında uluslararası bir müteahhitlik şirketinin karayolu köprü yapımı için kullanacağı taşeron firma seçimi problemini ele almışlardır. Problemin çözümünde çkkv ve bulanık mantık kullanmışlardır. İraz vd. [18] çalışmalarında Konya ilinde faaliyet gösteren KOBİ'lerin yenilik yönetimi açısından dış kaynak kullanma eğilimlerini analiz etmişlerdir. Rençber ve Kazan [19] çalışmalarında büyük çaplı bir inşaat projesi için taşeron firma seçimi problemini ele almışlardır. Firma seçerken dikkate alınacak kriterlerin önemi karşılaştırmak ve tekliflerin değerlendirilmesini yapmak için AHP yöntemini kullanmışlardır. Bedir vd. [20] dış kaynak kullanımı için AHP ve PROMETHEE yöntemlerini kullanmışlardır. Kalkan vd. [21] çalışmalarında Ankara Halk Sağlığ 1 Müdürlüğü’ne bağlı sağlık kuruluşlarının dış kaynak kullanımının müdürlüğe maliyetlerini tespit etmişlerdir. Görener ve Sabuncuoğlu [22] çalışmalarında yüklenici seçiminde çok kriterli karar verme yöntemlerinde AHP ve TOPSIS yöntemleriyle bir yaklaşım önermişlerdir ve inşaat endüstrisinden örnek bir uygulama yapmışlardır.

\section{COK KRİTERLİ KARAR VERME}

Çok kriterli karar verme, Karar Bilimlerinin bir alt dalıdır. Karar verme sürecini kriterlere göre modelleme ve analiz sürecine dayanır. Literatürde en sık rastlanan çok kriterli karar verme yöntemleri AHP, TOPSIS, VIKOR, ELECTRE ve PROMETHEE' dir [23].

\subsection{ANP Yöntemi}

Analitik A $\breve{g}$ Prosesi (ANP), Analitik Hiyerarşi Proses (AHP) yönteminden daha genel bir yaklaşım olarak Thomas L. Saaty tarafindan geliştirilmiş çok kriterli bir karar verme tekniğidir ve AHP gibi ikili karşılaştırma mantığıyla çalışır [24]. Analitik Ağ Prosesi, faktörler arasındaki ilişkilerin dikkate alınmasını gerektiren karar problemlerinin modellenmesinde kullanılabilecek ve daha etkin sonuçlara ulaşılmasını sağlayacak yöntemdir. ANP yönteminde, bir amaç ve hedefi etkileyen faktörler, birbirlerine olan etkilerine göre gruplandırılmakta ve amaca uygun bir a $\breve{g}$ (network) şeklinde model kurulmaktadır. ANP'nin AHP'ye göre farklılığı, yukarıdan aşağıya doğru bir hiyerarşik yapı yerine etkileşimli (ağ/network biçiminde) bir hiyerarşik yapı kullanılmasıdır. Ayrıca AHP yönteminde karşılaşılan önemli bir sorun sıra değişimidir. Sıra değişimi; belirli bir faktör kümesine göre belirlenen alternatif önceliklerinin, yeni bir alternatif eklendiğinde veya çıkarıldığında değişmesidir. Bu sorun ANP yönteminde azaltılmıştır [25]. ANP yönteminin adımları;

Adım 1: Problemin tanımlanması ve modelin kurulması

Adım 2: İkili karşılaştırma matrisinin oluşturulması

Adım 3: Matrislerin tutarlılık analizi ve süper matrisin oluşturulması

Adım 4: Süper matrisin oluşturulması

Adım 5: En iyi alternatifin oluşturulması şeklindedir.

ANP yönteminin birçok uygulama alanı bulunmaktadır. Lin vd. [26], Yurdakul [27], Bhattacharya [28] vd. performans ölçümünde, Meade ve Presley [29], Hamurcu ve Eren [30] proje değerlendirmede, Gencer ve Gürpınar [31] tedarikçi seçiminde, Cheng vd. [32], Burnaz ve Topçu [33], Partovi [34], Tuzkaya vd. [35] tesis yeri seçiminde, Özcan vd. [36] güneş enerji santrali seçiminde,Özcan vd. [37] enerji yatırımlarının değerlendirilmesinde, Bağ vd. [38] hemşire çizelgeleme probleminin çözümünde , Özder vd. [39] paket program seçiminde ANP yöntemini kullanmışlardır.

\subsection{PROMETHEE Yöntemi}

PROMETHEE Brans [40] tarafından geliştirilmiş bir çoklu karar verme yöntemidir. Yöntem karar noktalarının sırasını, PROMETHEE I (kısmi siralama) ve PROMETHEE II (tam sıralama) ana aşamalarıyla belirler. PROMETHEE yöntemi karar noktalarının değerlendirme faktörlerine göre ikili kıyaslamalarına dayanır. Ancak diğer çoklu karar verme yöntemlerinden temel farkı, değerlendirme faktörlerinin birbirleri arasında ilişki düzeyini gösteren önem ağırlıklarının yanı sıra, her bir değerlendirme faktörünün kendi iç ilişkisini de dikkate almasıdır.

PROMETHEE yöntemi ile birçok alanda uygulanmaktadır. Bedir ve Eren [41] personel seçiminde, Bedir vd. [42] öğrenci seçiminde, Özder vd.[43] akademik personel seçiminde, Bedir vd.[44] lojistik firma seçiminde, Bedir vd. [45] demontaj hattı dengelemede, Taş vd. [46] monoray hat tipinin belirlenmesinde PROMETHEE yöntemini kullanmıştır.

\subsubsection{PROMETHEE yöntemi aşamaları}

PROMETHEE yöntemi, diğer çok kriterli karar verme metotları ile uygulama ve kapsam açısından karşılaştırıldığında gerçek değerler ile ifade edilebilen çok sayıda kriter için uyarlanabilir basit bir yöntemdir. PROMETHEE yöntemi 7 adımdan oluşmaktadır [41]:

Adım 1: Veri matrisinin oluşturulması: $\mathrm{W}=$ $(\mathrm{w} 1, \mathrm{w} 2, \ldots, \mathrm{wk})$ ağırlıkları ile $\mathrm{k}$ kriter $\mathrm{c}=(\mathrm{fl}, \mathrm{f} 2, \ldots, \mathrm{fk})$ tarafindan değerlendirilen alternatiflere $\mathrm{A}=(\mathrm{a}, \mathrm{b}, \mathrm{c}, \ldots)$ ilişkin veri matrisi, Tablo 1'deki gibi oluşturulur. 
Tablo 1. PROMETHEE Veri Matrisi

\begin{tabular}{|l|c|c|c|c|c|c|}
\hline \multicolumn{2}{|c|}{} & \multicolumn{5}{|c|}{ Değerlendirme Faktörleri } \\
\cline { 3 - 8 } \multicolumn{2}{|c|}{ Karar Noktaları } & $f_{1}$ & $f_{2}$ & $f_{3}$ & $\cdots$ & $f_{k}$ \\
\hline & B & $f_{1}(\mathrm{~A})$ & $f_{2}(\mathrm{~A})$ & $f_{3}(\mathrm{~A})$ & $\cdots$ & $f_{k}(\mathrm{~A})$ \\
\cline { 2 - 7 } & $\mathrm{C}$ & $f_{1}(\mathrm{~B})$ & $f_{2}(\mathrm{~B})$ & $f_{3}(\mathrm{~B})$ & $\cdots$ & $f_{k}(\mathrm{~B})$ \\
\cline { 2 - 7 } & $\cdots$ & $f_{2}(\mathrm{C})$ & $f_{3}(\mathrm{C})$ & $\cdots$ & $f_{k}(\mathrm{C})$ \\
\hline & $w_{i}$ & $w_{1}$ & $w_{2}$ & $w_{3}$ & $\cdots$ & $w_{k}$ \\
\hline Ağırlıklar & & & & & $\cdots$ & $\cdots$ \\
\hline
\end{tabular}

Adım 2: Kriterler için tercih fonksiyonların tanımlanması: Yöntemin uygulanmasında kullanılacak 6 farklı tercih fonksiyonu Tablo 2'de gösterilmiştir.

Tablo 2. Tercih fonksiyonları

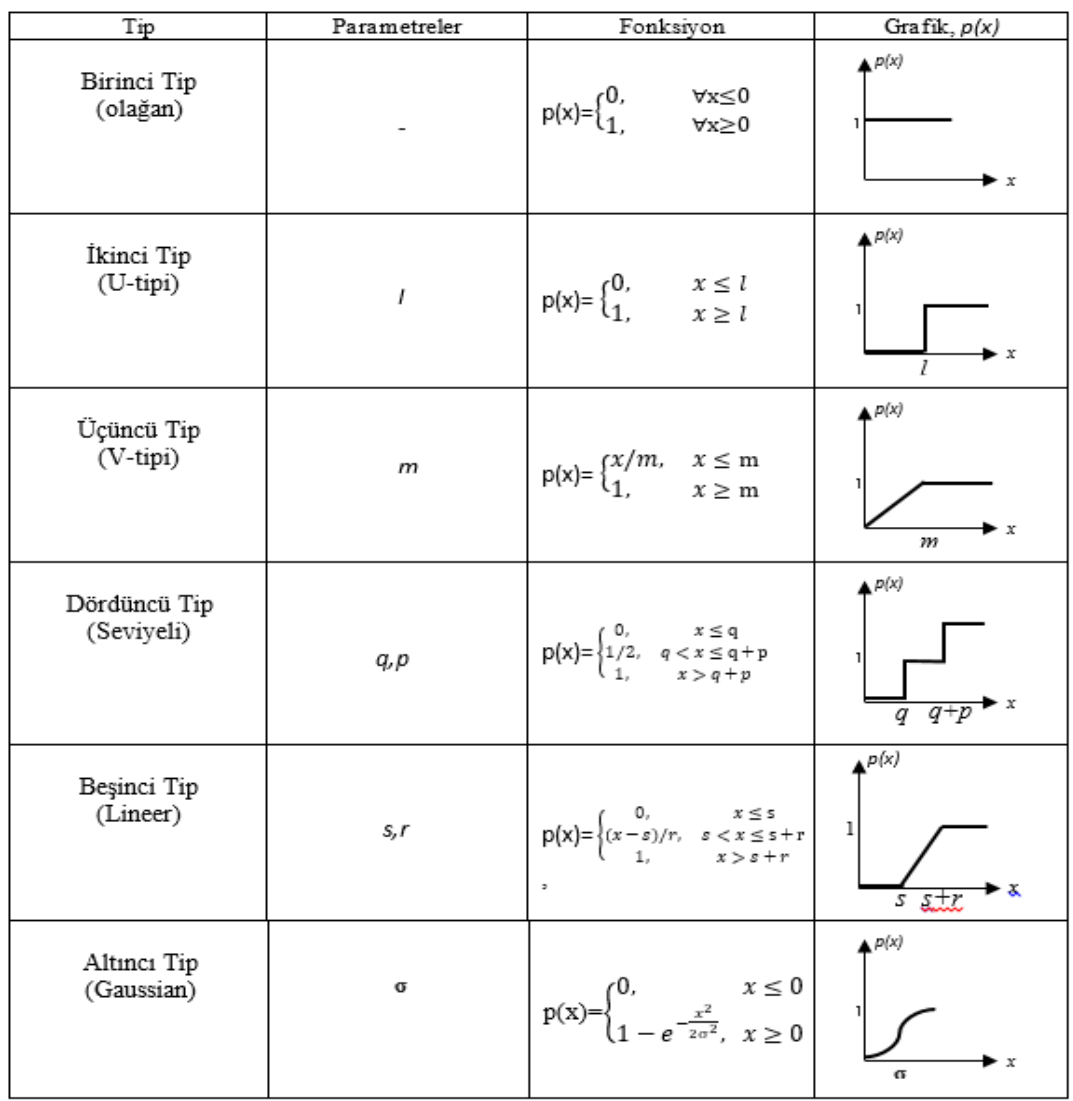

Adım 3: Ortak tercih fonksiyonlarının belirlenmesi: Alternatifler için belirlenen ortak tercih fonksiyonlarının şematik gösterimi Şekil 1'de verilmiş olup a ve b alternatifleri için ortak tercih fonksiyonu Eşitlik 4.1 ile belirlenir.

$$
\mathrm{P}(\mathrm{a}, \mathrm{b})=\left\{\begin{array}{lr}
0 & , f(a) \leq f(b) \\
p[f(a)-f(b)], f(a)>f(b)
\end{array}\right\}
$$

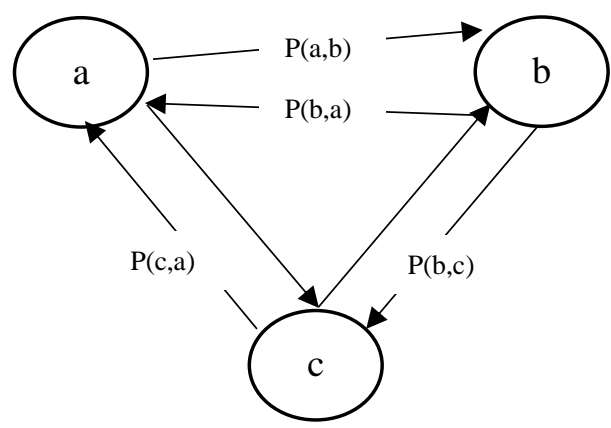

Şekil 1. Ortak tercih fonksiyonlarının şematik gösterimi 
Adım 4: Tercih indekslerinin belirlenmesi: Ortak tercih fonksiyonlarından hareketle her alternatif çifti için tercih indeksleri belirlenir. Wi $(\mathrm{i}=1,2, \ldots, \mathrm{k})$ ağırlıklarına sahip olan $\mathrm{k}$ kriter tarafindan değerlendirilen $\mathrm{a}$ ve $\mathrm{b}$ alternatiflerinin tercih indeksi Eşitlik 4.2 ile hesaplanır.

$$
\pi(\mathrm{a}, \mathrm{b})=\frac{\sum_{i=1}^{k} w_{i} P_{i}(a, b)}{\sum_{i=1}^{k} w_{i}}
$$

Adım 5: Alternatifler için pozitif $\left(\Phi^{+}\right)$ve negatif $\left(\boldsymbol{\Phi}^{-}\right)$üstünlükler belirlenmesi: A alternatifi için pozitif ve negatif üstünlük şematik olarak Şekil 2'de gösterilmiş olup pozitif üstünlük Eşitlik 4.3, negatif üstünlük ise eşitlik 4.4 ile hesaplanır.

$$
\begin{gathered}
\Phi^{+}(a)=\frac{1}{n-1} \sum \pi(a, b) \\
\Phi^{-}(a)=\frac{1}{n-1} \sum \pi(b, a)
\end{gathered}
$$
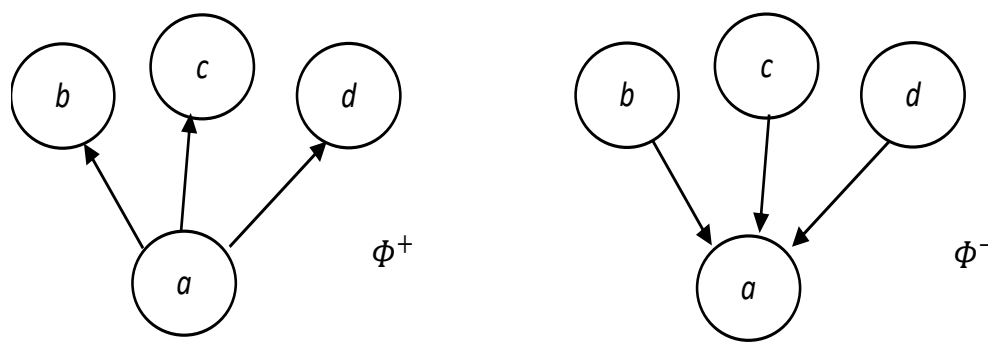

Şekil 2. a alternatifi için hesaplanan pozitif ve negatif üstünlük

Adım 6: PROMETHEE I ile alternatifler için kısmi önceliklerin belirlenmesi: Kısmi öncelikler alternatiflerin birbirlerine göre tercih edilme durumlarının, birbirinden farksız olan alternatiflerin ve birbirleriyle karşılaştırılamayacak olan alternatiflerin belirlenmesini sağlar.

Adım 7: PROMETHEE II ile alternatifler için tam önceliklerin belirlenmesi: Eşitlik 4.11 yardımıyla her bir alternatif için tam öncelikler hesaplanır. Hesaplanan tam öncelik değerleri ile bütün alternatifler aynı düzlemde değerlendirerek tam siralama belirlenir.

$\Phi(\mathrm{a})=\Phi^{+}$(a) $-\Phi^{-}(\mathrm{a})$

a ve $b$ gibi iki alternatif için hesaplanan tam öncelik değerine bağlı olarak aşağıda verilen kararlar alınır.

- $\Phi($ a) $>\Phi($ b) ise, a alternatifi daha üstündür,

- $\Phi(\mathrm{a})=\Phi(\mathrm{b})$ ise, a ve b alternatifleri farksızdır.

\section{5. ÖRNEK UYGULAMA}

Problemin akış şeması Şekil 3 'te gösterildiği gibidir.

\subsection{Problemin Tanımlanması}

$\mathrm{Bu}$ çalışmada Kırıkkale' de faaliyet gösteren bir gayrimenkul ve proje firmasının anahtar teslim tadilat işi için seçeceği taşeron firmanın belirlenmesi amaçlanmıştır.

\subsection{Alternatiflerin Belirlenmesi}

İşi alacak olan alternatif şirketler Ankara'da faaliyet gösteren MAK, MSK, VEFA ve UMUT'dur

\subsection{Kriterlerin Belirlenmesi}

Müteahhit firma bünyesinde çalışan 1 inşaat mühendisi, 1 endüstri mühendisi ve 1 proje müdürünün değerlendirmesi ve literatürün incelenmesi sonucunda belirlenen kriterler şu şekildedir;

- Maliyet (M) : Firmaların yapılacak olan iş için standart bir daire için belirledikleri teklifin maliyetini gösterir.

- Finansal kapasite (FK) :Yapılacak olan işlerin aksamaması açısından firmaların finansal kapasiteleri önemlidir. Bu kriter firmaların sermayelerini göstermektedir.

- Geçmiş performans (GP) : Aday firmaların piyasada daha önceden yaptıkları işler referans alınarak firma hakkında fikir sahibi olunmasına etkiyen kriterdir.

- İş gücü (İG) : Aday firmaların mevcut personellerinin işe hakimiyetleri ve personellerin sayılarına göre değişen kriterdir.

- Güvenlik $(\mathrm{G})$ : Aday firmaların yaptıkları işleri önceden belirledikleri tarihlerde gerçekleştirebilmesi durumu, yapılan işin kalitesi ve uzun süreli ilişkilerdeki faaliyetlerini içeren kriterdir. 


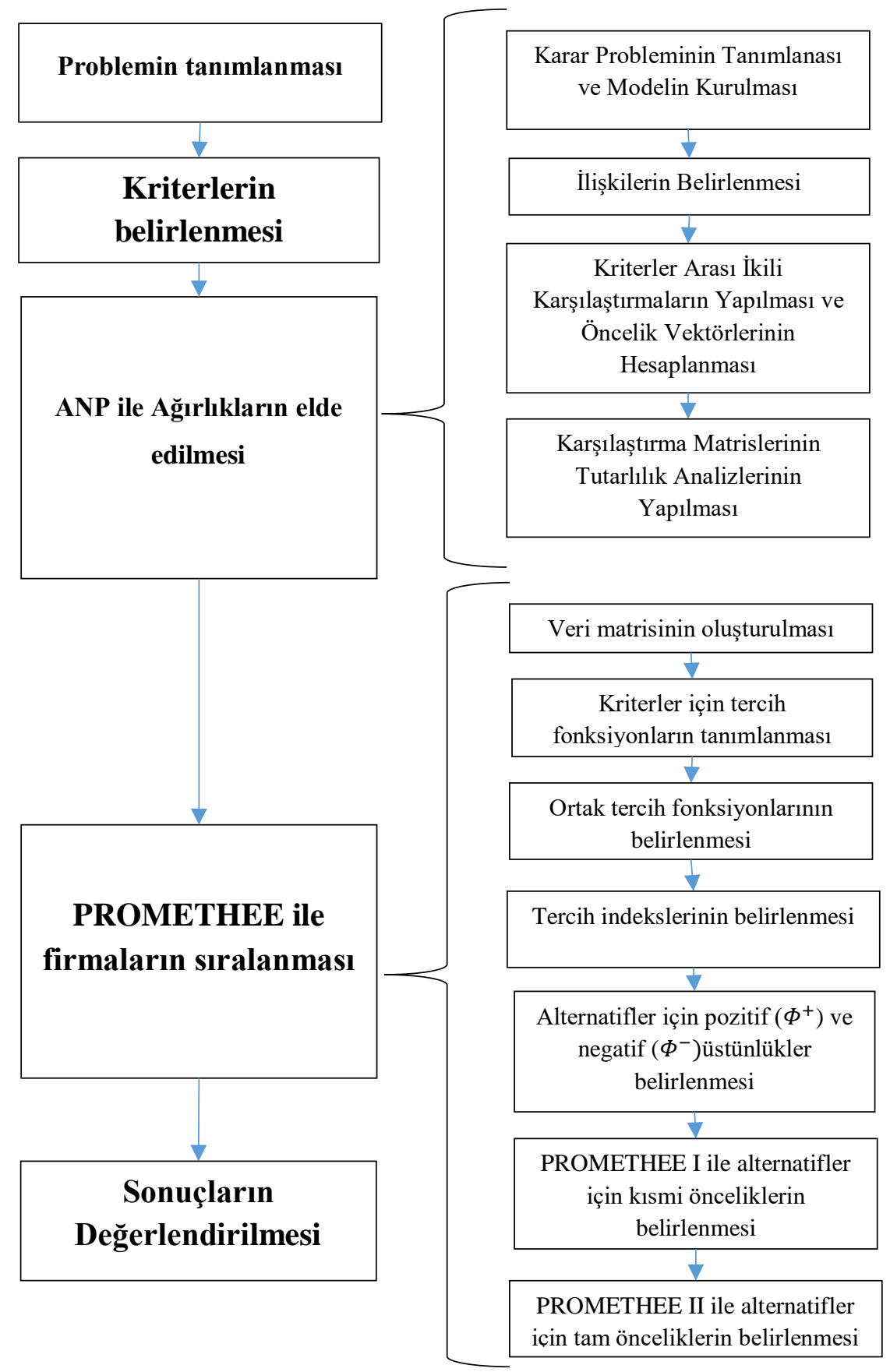

Şekil 3. Problem akış şeması

\subsection{Problemin Çözümü}

ANP yöntemi ile en uygun taşeron firmanın seçimi yapılırken SUPER DESICION programından faydalanılmıştır. ANP yöntemi ile elde edilen kriter ağırlıkları Tablo 3'de gösterilmektedir.
Tablo 3 ANP kriter ağırlıkları

\begin{tabular}{|c|c|}
\hline Kriterler & Ăğrlık \\
\hline Finansal Kapasite & 0,0797 \\
\hline Geçmiş performans & 0,1553 \\
\hline Güvenlik & 0,3732 \\
\hline İş gücü & 0,1834 \\
\hline Maliyet & 0,2084 \\
\hline
\end{tabular}


PROMETHEE yöntemi ile çözüm yapmak için VISUAL PROMETHEE programı kullanılmıştır. PROMETHEE yönteminde ANP yönteminden elde edilen Tablo 3'deki ağırlıklar kullanılmıştır. Kriterlerin tamamı maksimizasyondur.

PROMETHEE yönteminde kriterler için tercih fonksiyonu uzman görüşü alınarak ve literatürde yer alan benzer çalışmalar incelenerek maliyet için 5 . tip, finansal kapasite ve güvenlik için 4. tip, Geçmiş performans ve iş gücü için 3. tip olarak belirlenmiştir. Eşik değerleri $\mathrm{q}=1 \mathrm{p}=2$ olacak şekilde işlemler yapılmıştır. PROMETHEE yönteminde çözüme ulaşmak için VISUAL PROMETHEE programında veri girişi Şekil 4' te gösterildiği gibi yapılmıştır.

PROMETHEE yöntemi ile elde edilen siralama Tablo 4' teki gibi elde edilmiştir.

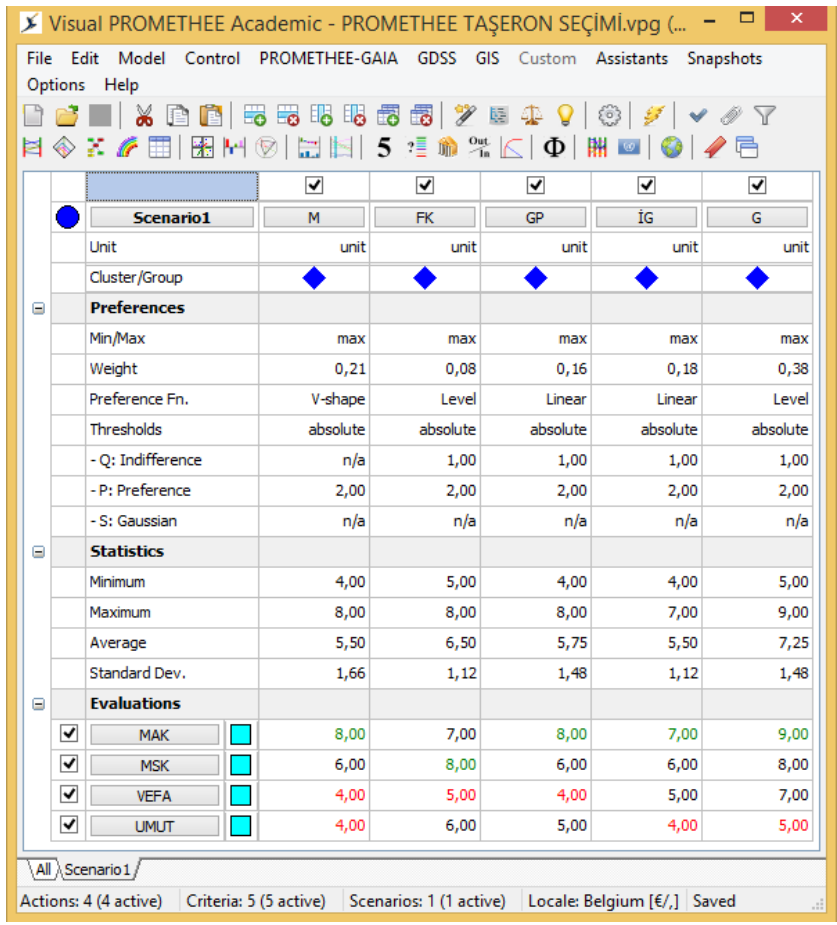

Şekil 4. PROMETHEE veri girişi

Tablo 4. PROMETHEE sonucu

\begin{tabular}{|c|c|c|c|}
\hline Alternatifler & $\boldsymbol{\Phi}_{\text {net }}$ & $\boldsymbol{\Phi}^{+}$ & $\boldsymbol{\Phi}^{-}$ \\
\hline MAK & 0,8081 & 0,8081 & 0,0000 \\
\hline MSK & 0,3199 & 0,5286 & 0,2088 \\
\hline UMUT & $-0,5320$ & 0,0000 & 0,5320 \\
\hline VEFA & $-0,5960$ & 0,0135 & 0,6094 \\
\hline
\end{tabular}

PROMETHEE I sonucuna göre MAK hem MSK, UMUT ve VEFA firmalarına göre hem pozitif hem de negatif üstün olduğundan MAK diğer alternatiflerden üstündür. Özellikle güvenlik kriterinde diğer firmalardan olan MAK şirketi finansal kapasitesi diğer alternatiflerden düşük olmasına rağmen bütün kriterler için değerlendirildiğinde en iyi alternatif olmaktadır

Net üstünlükler hesaplandığında PROMETHEE II sonucuna göre siralama MAK-MSK-UMUT ve VEFA şeklinde belirlenmiştir.

\section{SONUC}

$\mathrm{Bu}$ çalışmada anahtar teslim tadilat işi için müteahhit firmanın alt yüklenici seçim problemi ele alınmıştır. Problemin çözümünde çok kriterli karar verme yönteminden ANP ve PROMETHEE yöntemleri kullanılmıştır. İleride yapılacak çalışmalarda problemin çözümü için yeni alternatifler eklenebilir. Kriterlerin öncelikleri için hedef programlama ya da bulanık mantık kullanılabilir. Diğer çok kriterli karar verme yöntemleri uygulanarak sonuçları karşılaştırılabilir.

\section{KAYNAKLAR}

[1] Hatush, Z., Skitmore, M., Contractor selection using multicriteria utility theory: an additive model" Building and environment, 33(2), 105-115, 1998

[2] Topçu, Y.I.. A decision model proposal for construction contractor selection in Turkey, Building and environment, 39(4), 469-481, 2004.

[3] Mulavdic, E., Multi Criteria Optimization of Construction Technology of Residential Building Upon The 
Principles of Sustainable Development, Thermal Science, 9(3), 39-52, 2005.

[4] Gül, H., Dış kaynak kullanma nedenleri ve taşıdığ riskler: imalat sanayiinde bir uygulama, Yönetim ve Ekonomi Araştırmaları Dergisi, 3(4), 157-184, 2005.

[5] Singh, D., Tiong, R.L., A fuzzy decision framework for contractor selection, Journal of Construction Engineering and Management, 131(1), 62-70, 2005.

[6] Tzeng, G. H., Lin, C. W., Opricovic, S., Multi-criteria analysis of alternative-fuel buses for public transportation, Energy Policy, 33(11), 1373-1383, 2005.

[7] Soner, S., Önüt, S., Multi-Criteria Supplier Selection: An ELECTRE-AHP Application, Sigma, 4, 110-120, 2006.

[8] Opricovic, S., Multicriteria optimization of civil engineering systems, Faculty of Civil Engineering, Belgrade, 2(1), 5-21, 1998.

[9] Chu, M.T., Shyu, J., Tzeng, G.-H., Khosla, R., Comparison Among Three Analytical Methods For Knowledge Communities Group Decision Analysis .Expert Systems with Applications, 33(4), 1011-1024, 2007.

[10] Lixin, D., Ying, L., Zhiguang, Z., Selection of logistics service provider based on analytic network process and VIKOR algorithm. InNetworking, Sensing and Control, ICNSC, IEEE International Conference, 1207-1210, April 2008.

[11] Wua, H.Y., Tzeng, G.H., Chen, Y.H., A Fuzzy Mcdm Approach For Evaluating Banking Performance Based On Balanced Scorecard, Expert Systems with Applications, 36:10135-10147, 2009.

[12] Ertuğrul, İ., Karakaşoğlu, N., Banka şube performanslarının VIKOR yöntemi ile değerlendirilmesi. Endüstri Mühendisliği Dergisi, 20(1), 19-28, 2009.

[13] Sanayei, A., Mousavi, S. F., Yazdankhah, A., Group decision making process for supplier selection with VIKOR under fuzzy environment. Expert Systems with Applications, 37(1), 24-30, 2010.

[14] Kaya, T., Kahraman, C., Multicriteria Renewable Energy Planning Using an Integrated Fuzzy VIKOR \& AHP Methodology: The Case of Istanbul, Energy, 35:2517-2527, 2010.

[15] Akyüz, G., Bulanık VIKOR yöntemi ile tedarikçi seçimi, Atatürk Üniversitesi İktisadi ve İdari Bilimler Dergisi, 26(1), 197-214, 2012.

[16] Ravi, V., Selection of third-party reverse logistics providers for End-ofLife computers using TOPSIS-AHP based approach, International Journal of Logistics Systems and Management, 11(1), 24-37, 2012.

[17] Abbasianjahromi, H., Rajaie, H., Shakeri, E., A Framework for Subcontractor Selection in the Construction Industry, Journal of Civil Engineering and Management, 19(2), 158-168, 2013.

[18] İraz, R., Çakıcı, A. B., Tekin, İ. Ç., Yenilik yönetimi açısından KOBI'lerde dış kaynak kullanımının araştırılması: Konya ili örneği, Global Journal of Economics and Business Studies, 3(6), 51-68, 2014.

[19] Rençber, Ö. F., Kazan, H., Büyük Çaplı Projelerde Taşeron Firma Seçiminde Teklif Değerlendirme: Analitik Hiyerarşi Süreci Yöntemi İle Karar Verme, International Journal of Social Science Research, 3 (4), 11-24, 2014.
[20] Bedir N., Özder E.H., Eren T., The Third Party Logistics Firm Selection Using Of AHP-PROMETHEE Methods, XIII. International Logistics and Supply Chain Congress 22, Izmir, Turkey, 23 October 2015.

[21] Kalkan, M., Sökmen, A., Bıyık, Y., Sağlık hizmetlerinde dış kaynak kullanımı: Ankara halk sağlığı müdürlüğü uygulaması, İktisadi ve İdari Bilimler Fakültesi Dergisi, 17(2), 35-56, 2015.

[22] Görener, A., Sabuncuoglu, O., Bulanık TOPSIS Metodu ile Karar Verme: İnşaat Projelerinde Yüklenici Seçimi (Decision Making Through the Fuzzy TOPSIS Method: Contractor Selection in Construction Projects).International Journal of Research in Business and Social Science, 5(2), 71 82,2016

[23] Bedir, N., Özder, E. H., Eren, T., Course Selection with AHP \& PROMETHEE Methods for Post Graduate Students: An Application in Kirikkale University Graduate School of Natural and Applied Sciences, The 3rd International Conference on Industrial Engineering and Applications (ICIEA) in Hong Kong, during April 28-30, 2016.

[24] Bağ, N., Özdemir, N. M., Eren, T., 0-1 Hedef Programlama ve ANP Yöntemi ile Hemşire Çizelgeleme Problemi Çözümü, International Journal of Engineering Research and Development, 4(1), 2-6, 2012.

[25] Timor, M., Analitik Hiyerarşi Prosesi. İstanbul, Türkmen Kitabevi, 2001.

[26] Lin C.T., Lee C. and Chen W.Y., "An Expert System Approach To Assess Service Performance Of Travel Intermediary", Expert Systems with Applications, 36, 2987 2996, (2009). 122

[27] Yurdakul M., "Measuring Long-Term Performance Of A Manufacturing Firm Using The Analytic Network Process", International Journal of Production Research, 41(11):2501-2529, (2003).

[28] Bhattacharya, A., Mohapatra, P., Kumar, V., Dey, P. K., Brady, M., Tiwari, M. K., \& Nudurupati, S. S. (2014). Green supply chain performance measurement using fuzzy ANPbased balanced scorecard: a collaborative decision-making approach. Production Planning \& Control, 25(8), 698-714.

[29] Hamurcu M., Eren T., "Bulanık ANP Kullanılarak Raylı Sistem Projelerinin Önceliklendirilmesi” Transist 10. Uluslararası Ulaşım Teknolojileri Sempozyumu ve Fuarı, 24 Kasım 2017, 89-97, İstanbul, Türkiye.

[30] Meade M.L. and Presley A., "R\&D Project Selection Using The Analytic Network Process", IEEE Transactions on Engineering Management, 49(1): 59-66, 2002.

[31] Gencer C. and Gürpınar D., "Analytic Network Process In Supplier Selection: A Case Study İn An Electronic Firm”, Applied Mathematical Modelling, 31, 2475-2486, 2007.

[32] Cheng, E.W. L., Li, H. ve Y. Ling, "The Analytic Network Process Approach to Location Selection: A Shopping Mall Illustration", Construction Innovation, 5, 8397, 2005.

[33] Burnaz, S. ve İ. Topcu, "A Multiple-Criteria DecisionMaking Approach for The Evaluation of Retail Location", Journal of Multi-Criteria Decision Analysis, 14, 67-76, 2006.

[34] Partovi, F.Y., "An Analytic Model for Locating Facilities Strategically", The International Journal of Management Science, 34, 41-55, 2006. 
[35] Tuzkaya,G., Önüt, S., Tuzkaya, U.R., Gülsün B., “An Analytic Network Process Approach for Locating Undesirable Facilities: An Example from Istanbul", Journal of Environmental Management, 88(4):970-983, 2008.

[36] Özcan, E.C., Özcan, N.A., Eren, T., "CSP Teknolojisine Sahip Güneş Enerjisi Santrallarının Kombine ANPPROMETHEE Yaklaşımı ile Seçimi”, Başkent Üniversitesi, Ticari Bilimler Fakültesi Dergisi, 1 (1), 18-44, 2017.

[37] Özcan, E.C., Ünlüsoy, S., Eren, T., “ANP ve TOPSIS Yöntemleriyle Türkiye'de Yenilenebilir Enerji Yatırım Alternatiflerinin Değerlendirilmesi”, Selcuk University Journal of Engineering, Science and Technology, 5 (2), 204219, 2017.

[38] Bağ N., Özdemir M., Eren T., "0-1 Hedef Programlama ve ANP Yöntemi ile Hemşire Çizelgeleme Problemi Çözümü” International Journal of Engineering Research and Development, 4 (1), 2-6, 2012.

[39] Özder, E., Gür Ş., Eren T., İşletmelerde Yönetimin Etkinliğini Arttırmak İçin ANP Ve TOPSIS Yöntemleri İle Muhasebe Paket Programı Seçimi, The 13th International Accounting Conference, s. 13-14, İzmir, Turkey, October 20-21, 2016.

[40] Brans, J.P. L'ingenierie de la decision: Elaboration d'instruments d'aide a la decision. La Methode PROMETHEE. Universite Laval, Colloque d'aide a la Decision, Quebec, Canada,183-213, 1982.

[41] Bedir, N.,Eren, T., “AHP-PROMETHEE Yöntemleri
Entegrasyonu ile Personel Seçim Problemi: Perakende Sektöründe Bir Uygulama", Social Sciences Research Journal,4 (4), 46-58, 2015.

[42] Bedir, N., Özder, E. H., Eren, T., “ Course Selection with AHP \& PROMETHEE Methods for Post Graduate Students: An Application in Kirikkale University Graduate School of Natural and Applied Sciences" The 3rd International Conference on Industrial Engineering and Applications (ICIEA 2016) in Hong Kong, during April 2830.

[43] Özder, E. H., Bedir, N., Eren, T., "Academic Staff Selection With Anp \& Promethee Method: A Case Study In Turkey" International Academic Conference on Engineering, Technology and Innovations (IACETI), Dubai, UAE, March 5th, 2016.

[44] Bedir N., Özder E.H., Eren T.,"The Third Party Logistics Firm Selection Using Of AHP-PROMETHEE Methods", XIII.International Logistics and Supply Chain Congress 22-23 October 2015, Izmir, Turkey.

[45] Bedir, N., Alağaş, H.M., Eren, T., “ Çok Ölçütlü Karar Verme İle Demontaj Hattı Dengeleme”, Uluslararası Mühendislik Araştırma ve Geliştirme Dergisi, 9(1), 11-18, 2017.

[46] Taş, M., Özlemiş, Ş.N., Hamurcu, M., Eren, T., “Ankara'da AHP Ve PROMETHEE Yaklaşımıyla Monoray Hat Tipinin Belirlenmesi”, Ekonomi, Issletme, Siyaset ve Uluslararası İlişkiler Dergisi, 3 (1): 64-89, 2017 